\title{
Experimental and Numerical Investigations on Feasibility and Validity of Prismatic Rock Specimen in SHPB
}

\author{
Xibing Li, ${ }^{1}$ Tao Zhou, ${ }^{1,2}$ Diyuan Li, ${ }^{1}$ and Zewei Wang ${ }^{1}$ \\ ${ }^{1}$ School of Resources and Safety Engineering, Central South University, Changsha 410083, China \\ ${ }^{2}$ Department of Civil and Environmental Engineering, The Hong Kong Polytechnic University, Hung Hom, Hong Kong \\ Correspondence should be addressed to Diyuan Li; diyuan.li@csu.edu.cn
}

Received 24 February 2016; Accepted 18 April 2016

Academic Editor: Yuri S. Karinski

Copyright (c) 2016 Xibing Li et al. This is an open access article distributed under the Creative Commons Attribution License, which permits unrestricted use, distribution, and reproduction in any medium, provided the original work is properly cited.

\begin{abstract}
The paper presents experimental and numerical studies on the feasibility and validity of using prismatic rock specimens in split Hopkinson pressure bar (SHPB) test. Firstly, the experimental tests are conducted to evaluate the stress and strain uniformity in the prismatic specimens during impact loading. The stress analysis at the ends of the specimen shows that stress equilibrium can be achieved after about three wave reflections in the specimen, and the balance can be well maintained for a certain time after peak stress. The strain analysis reveals that the prismatic specimen deforms uniformly during the dynamic loading period. Secondly, numerical simulation is performed to further verify the stress and strain uniformity in the prismatic specimen in SHPB test. It indicates that the stress equilibrium can be achieved in prismatic specimen despite a certain degree of stress concentration at the corners. The comparative experiments demonstrate that the change of specimen shape has no significant effect on dynamic responses and failure patterns of the specimen. Finally, a dynamic crack propagation test is presented to show the application of the present work in studying fracturing mechanisms under dynamic loading.
\end{abstract}

\section{Introduction}

Rock mass is a heterogeneous and anisotropic compound structure, containing a great number of flaws such as joints, bedding planes, fractures, microcracks, and faults. The existence of discontinuities, joints, or cracks in rock has at least two effects: (i) decreasing the strength and stiffness of the rock directly and (ii) a source of initiation of new discontinuities which in turn may propagate and link with other cracks and further decrease the strength and the stiffness of the rock [1]. Therefore, it is of great significance to investigate the rock properties and crack initiation, propagation, and failure mechanisms under static and dynamic loading (e.g., blast, impact, and earthquake) for the sake of designing and assessing the stability of underground mining and geotechnical engineering.

In the past decades, numerous experiments have been conducted to study the mechanical properties and cracking processes of rock and rock-like specimens containing single or multiple preexisting flaw(s) under quasistatic compressive loading. Natural rocks such as granite $[2,3]$, marble $[4,5]$, and sandstone $[6,7]$ have been tested. Meanwhile, model materials (rock-like materials) such as gypsum [8-10] and artificial sandstones $[11,12]$ have been also tested. In these tests, prismatic specimens with a height-to-width ratio of 2.0 are mostly used, simply because it is more convenient and accurate to fabricate preexisting flaws and to observe the cracking processes from the plane surface of the prismatic specimen compared to the curved surface of the cylindrical specimen. However, few studies have been reported to observe the dynamic fracture propagation processes under dynamic loading [13-15]. Furthermore, the specimen shape used in these studies to observe the dynamic fracture propagation is also prismatic instead of cylindrical ones [14, 15]. However, the feasibility and validity of the prismatic brittle specimen have not been involved in these two studies $[14,15]$.

In terms of dynamic characteristics of rock materials, the split Hopkinson pressure bar (SHPB) system developed by Kolsky [16] has been widely used as a standard apparatus to measure the mechanical response of rock materials at high strain rates in the range of $10^{1} \sim 10^{3} \mathrm{~s}^{-1}$. In SHPB tests, cylindrical specimen in combination with round bars is used. The 
International Society of Rock Mechanics (ISRM) suggested that cylindrical specimens with diameter closing to $50 \mathrm{~mm}$ or at least 10 times the average grain size and slenderness ratios of $1: 1$ and $0.5: 1$ are recommended for small and large specimens, respectively [17]. However, as forgoing mentioned, it is inconvenient and very difficult to fabricate throughout two-dimensional (2D) flaws on cylindrical specimen with a diameter of about $50 \mathrm{~mm}$. Moreover, a highly flat surface is essential for the use of digital image correlation (DIC) technique and high-speed photography technique to monitor and record surface deformation characteristics and cracking behaviors during dynamic loading process. Therefore, as similar to quasistatic compressive tests, prismatic specimens should be taken into consideration in SHPB tests to study the dynamic cracking properties.

The use of noncylindrical specimens is not uncommon, since it is more convenient when testing materials (e.g., muscle tissue [18] and bone [19]) that are difficult to be fabricated into a standard shape. There have been some literatures discussing the feasibility of using noncylindrical specimens in SHPB tests. For instance, Sen et al. [20] discussed the use of hexagon and rectangle aluminum 6061 alloy specimens in SHPB test. Woldesenbet and Vinson [21] and Pankow et al. [22] analyzed the effects of specimen size and geometry on characterizing the dynamic properties of IM7/8551-7 graphite/epoxy composite and epoxy in SHPB testing. Their results showed that there were no significant effects of specimen size and geometry shape on the dynamic response of the material. However, it needs to be noted that these materials have two common features: (i) elastoplastic material and (ii) small size with diameter and length both less than or equal to $10 \mathrm{~mm}$. The elastoplastic property obviously differs from the mechanical properties of the rock material, since rock belongs to a quasibrittle material, and its failure strain is usually less than one percent. Moreover, the size of rock specimen is several times larger than that of the metal specimen according to ISRM's recommendation [17]. In view of this, the above conclusions may not be effectively applied to noncylindrical rock specimens in SHPB tests, and it is necessary to investigate the feasibility and validity of noncylindrical rock specimens in SHPB tests.

A fundamental assumption of SHPB compressive test is that the specimen should deform homogenously. This assumption can be fulfilled when using cylindrical specimens in combination with round bars. However, it may become a problem if utilizing prismatic specimens in combination with cylindrical bars in SHPB tests. Therefore, in order to verify the feasibility and validity of using prismatic rock specimens in SHPB tests, physical experiment and numerical simulation have been conducted to analyze the stress and strain evolution in the specimen during the impact loading process. In addition, comparative experiments are performed with prismatic and cylindrical specimens to discuss the geometry effect on the dynamic response of rocks under impact load with different strain rates. Finally, a set of dynamic crack propagation tests are conducted on prismatic marble specimens with a single preexisting flaw to demonstrate the application of the present work. It will be a benefit to investigate the dynamic fracture propagation and failure mode of rocks under dynamic loading.

\section{Methods}

2.1. Experimental Method. The SHPB tests are based on two fundamental assumptions: (i) one-dimensional elastic wave propagation in the bars and (ii) homogeneous deformation of the sample [23]. Zhou et al. [24] have confirmed that the former assumption can be fulfilled approximately by using long bars with a large length/diameter ratio, while the latter one is usually affected by axial and radial inertial effects and interfacial friction effect. These effects should be significantly minimized by wave shaping technique and fully lubricant on the interfaces between the bar and specimen.

Traditionally, a cylindrical specimen is usually used in SHPB compressive test. In this paper, prismatic rock specimens are used instead of cylindrical ones to check the stress and strain uniformity during the SHPB test. A fine-grained white marble rock is used to test for this research. Mineral composition analysis and optical microscopy analysis show that the tested marble is composed of calcite, dolomite, and quartz with an average grain size of $0.25 \mathrm{~mm}, 0.03 \mathrm{~mm}$, and $0.02 \mathrm{~mm}$, respectively. The mineral grain size varies from $0.02 \mathrm{~mm}$ to $0.35 \mathrm{~mm}$. Calcite is the dominant mineral (95\%) and then is followed by dolomite (4\%) and quartz (1\%). The physical and mechanical properties of the marble are listed in Table 1, which are obtained from the uniaxial compressive test and the Brazilian disc test under quasistatic load. The uniaxial compressive strength and the Brazilian tensile strength of the marble are about 100.0 MPa and 7.0 MPa, respectively.

The prismatic specimens are fabricated with a nominal size of $45 \mathrm{~mm} \times 45 \mathrm{~mm} \times 15 \mathrm{~mm}$ (length $\times$ width $\times$ thickness). The unevenness of the specimen surface is less than $0.02 \mathrm{~mm}$ and the tolerance of the impact loading surface perpendicularity to the specimen axis is less than $0.001 \mathrm{rad}$ as recommended by ISRM [17]. In order to verify the strain uniformity in the specimen during the SHPB test, four pieces of resistance strain gauges $(5 \times 3 \mathrm{~mm})$ are mounted on the specimen surface with fence length parallel to the loading direction. The layout of the strain gauges on the specimen's surface is shown in Figure 1. Strain gauges 1 and 3 are located near the edge of the back surface where $w=7.5 \mathrm{~mm}$, the distance from strain gauge center to the edge of the specimen, and strain gauges 2 and 4 are located in the center of the front and back surfaces, respectively. This arrangement of strain gauges can obtain the strain distribution between the two observation surfaces (gauges 2 and 4 ) and also across the transverse of the specimen (gauges 1,2, and 3).

The tests are carried out on a modified SHPB apparatus as described by Li et al. [25]. A schematic of the SHPB system is shown in Figure 2. It consists of a gas gun, a cone-shaped striker ( $0.36 \mathrm{~m}$ in length), an incident bar ( $2 \mathrm{~m}$ in length), a transmitted bar (1.5 $\mathrm{m}$ in length), an absorbing bar $(0.5 \mathrm{~m}$ in length), and a damper. The diameter, elastic modulus, $P$-wave velocity, and density of the elastic bars are $50 \mathrm{~mm}, 240 \mathrm{GPa}$, $5400 \mathrm{~m} / \mathrm{s}$, and $7,800 \mathrm{~kg} / \mathrm{m}^{3}$, respectively.

The specimen is sandwiched between the incident and transmitted bars. Two sets of resistance strain gauges are 
TABLE 1: Physical and mechanical properties of the tested marble.

\begin{tabular}{lc}
\hline Properties & Values \\
\hline Young modulus $E(\mathrm{GPa})$ & 44.7 \\
Poisson's ratio $\nu$ & 0.33 \\
Uniaxial compressive strength $\sigma_{c}(\mathrm{MPa})$ & 99.6 \\
Brazilian tensile strength $\sigma_{t}(\mathrm{MPa})$ & 7.0 \\
Density $\gamma\left(\mathrm{kg} / \mathrm{m}^{3}\right)$ & 2704.6 \\
Longitudinal wave velocity $V_{P}(\mathrm{~m} / \mathrm{s})$ & 3536.7 \\
Porosity $(\%)$ & $0.24-0.57$ \\
\hline
\end{tabular}

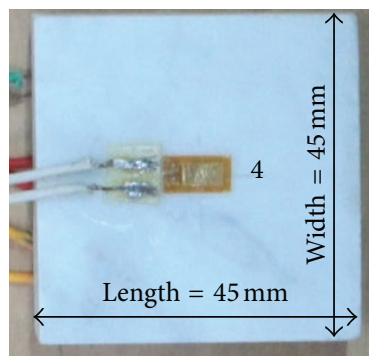

Front surface

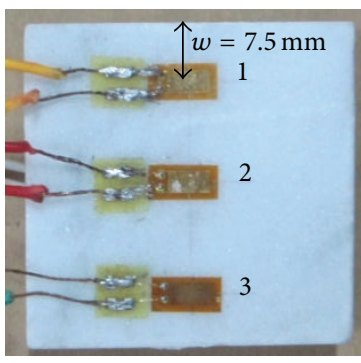

Back surface
FIGURE 1: The layout of strain gauges on prismatic marble specimen (impact loading direction: from right to left).

mounted on the center of incident and transmitted bars, respectively. During the test, the cone-shaped striker is launched from the gas gun at moderate velocity and impacts the front end of the incident bar. Then, a longitudinal compressive wave is generated and propagates down the incident bar toward the specimen. When the stress wave reaches the incident bar-specimen interface, a portion of the incident stress wave is reflected (reflected wave) and the remaining portion of the wave passes through the specimen to the transmitted bar (transmitted wave). These three elastic stress pulses in the incident and transmitted bars are recorded by the resistance strain gauges and denoted as the incident strain pulse $\varepsilon_{I}(t)$, reflected strain pulse $\varepsilon_{R}(t)$, and transmitted strain pulse $\varepsilon_{T}(t)$, respectively. Based on the one-dimensional stress wave propagation, the axial stress $\sigma(t)$, strain $\varepsilon(t)$, and strain rate $\dot{\varepsilon}(t)$ of the sample are expressed as follows:

$$
\begin{aligned}
& \sigma(t)=\frac{A_{e} E_{e}}{2 A_{s}}\left[\varepsilon_{I}(t)+\varepsilon_{R}(t)+\varepsilon_{T}(t)\right], \\
& \varepsilon(t)=\frac{C_{e}}{L_{s}} \int_{0}^{t}\left[\varepsilon_{I}(t)-\varepsilon_{R}(t)-\varepsilon_{T}(t)\right] d t, \\
& \dot{\varepsilon}(t)=\frac{C_{e}}{L_{s}}\left[\varepsilon_{I}(t)-\varepsilon_{R}(t)-\varepsilon_{T}(t)\right],
\end{aligned}
$$

where $A_{e}, C_{e}$, and $E_{e}$ are the cross-sectional areas, $P$-wave velocity, and Young's modulus of elastic bars, respectively. $A_{s}$ and $L_{s}$ are the cross-sectional area and the length of the specimen.
Furthermore, the dynamic forces on the incident barsample interface $\left(P_{1}\right)$ and the transmitted bar-sample interface $\left(P_{2}\right)$ are

$$
\begin{aligned}
& P_{1}=A_{e} E_{e}\left(\varepsilon_{I}+\varepsilon_{R}\right), \\
& P_{2}=A_{e} E_{e} \varepsilon_{T} .
\end{aligned}
$$

According to the principle of stress continuity on the barspecimen interfaces, the stress of the specimen at the incident end $\sigma_{\mathrm{SI}}$ and transmitted end $\sigma_{\mathrm{ST}}$ can be calculated as follows:

$$
\begin{gathered}
\sigma_{\mathrm{SI}}=\frac{P_{1}}{A_{s}}, \\
\sigma_{\mathrm{ST}}=\frac{P_{2}}{A_{s}} .
\end{gathered}
$$

During the SHPB test, the stresses in a prismatic rock specimen can be calculated by (1), (4), and (5), where the strain signals are obtained from the strain gauges mounted on the incident and transmitted bars. Meanwhile, the strain distributions in a prismatic rock specimen can be obtained by the strain gauges mounted on the specimen's surfaces. The stress and strain uniformity in a prismatic specimen by using round SHPB bars will be checked by these strain signals which are monitored by the oscilloscope.

2.2. Numerical Method. In order to further explore the stress uniformity in the prismatic specimen, numerical studies, by using a commercial finite-element software ABAQUS, are implemented to directly investigate and quantify the shape effect of the prismatic specimen based on the assumption that the specimen stress is uniformity under impact load. A three-dimensional model is created by using eight-node linear brick elements with reduced integration and hourglass control (element C3D8R) to represent the incident and transmitted bars and specimens. In the numerical modeling part, two types of specimen are used to make a comparison: a cylindrical specimen with dimension of $\Phi 50 \times 50 \mathrm{~mm}(D \times$ $L)$ and a rectangular prismatic specimen with edge size of $45 \times 45 \times 15 \mathrm{~mm}(L \times W \times T)$. The friction effect between the specimen and bar interfaces has been neglected. Frictionless tangential contact conditions are used for specimenbar interfaces. Half-sine stress wave obtained from physical experiment by the incident strain gauges is directly applied at the end of incident bar in the form of compressive pressure. Figure 3 shows a typical model of the SHPB equipment and the pulse applied at the end of incident bar. In order to analyze the stress uniformity in the specimen, some typical symmetric elements have been selected to monitor in the cylindrical and prismatic specimens, respectively.

\section{Results}

\subsection{Experimental Results}

3.1.1. Stress Equilibrium. The point that specimen reaches stress equilibrium before failure is essential to ensure the validity of the SHPB test. It can be checked by comparing 


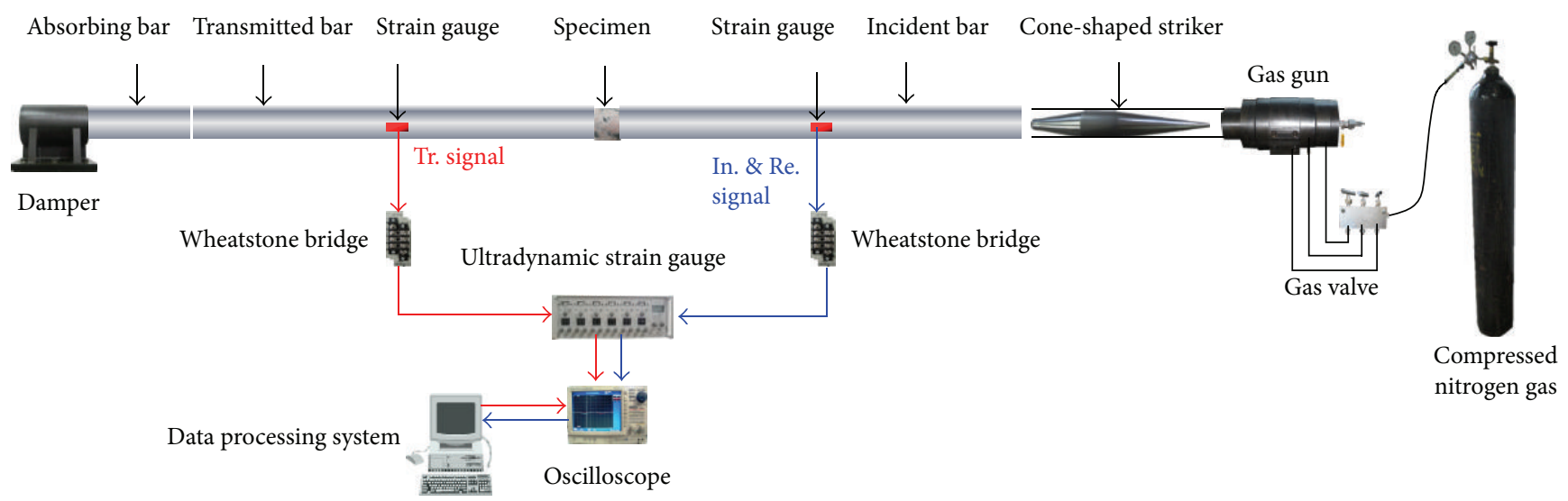

FIgURE 2: The schematic of the SHPB system.

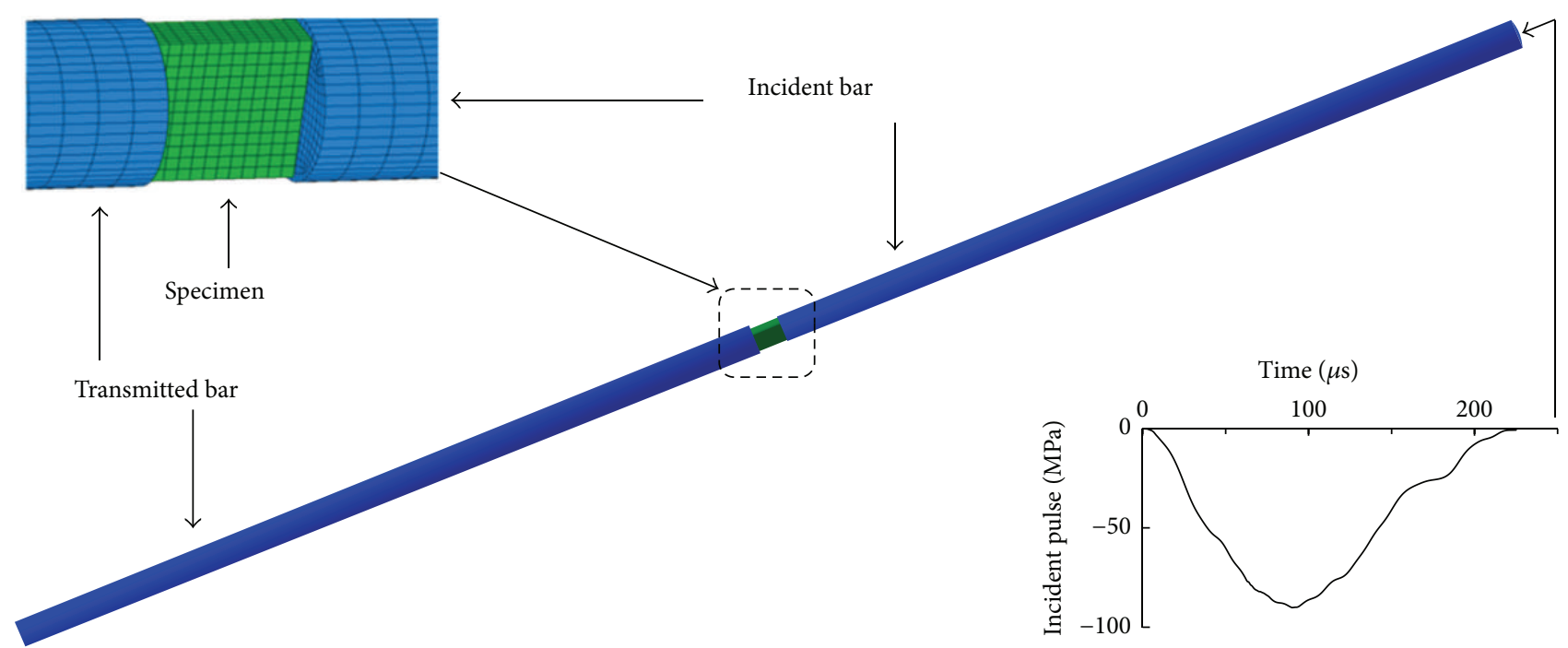

FIgURE 3: The model of SHPB device with incident pulse.

the stress histories at the two ends of the specimen. From this point, the stress equilibrium factor $\eta$ calculated by (6) can be used to evaluate the stress balance level in the specimen [26]:

$$
\eta=\frac{2\left(\sigma_{\mathrm{SI}}-\sigma_{\mathrm{ST}}\right)}{\sigma_{\mathrm{SI}}+\sigma_{\mathrm{ST}}} .
$$

After carefully calibrating the test system, specimen with loading ends fully lubricated is placed between the incident and transmitted bars and the striker is launched. In order to get good stress equilibrium in specimen, the striker is launched at a relatively low speed to avoid macro failure of the specimen. Figure 4 shows the original electrical signals captured from the strain gauges on the incident and transmitted bars under impact load. The average strain rate of the test is about $45 \mathrm{~s}^{-1}$.

The calculated result of stress equilibrium factor is shown in Figure 5. It can be seen that the stresses at the incident and transmitted ends are almost equal at the same time during most of the test period.

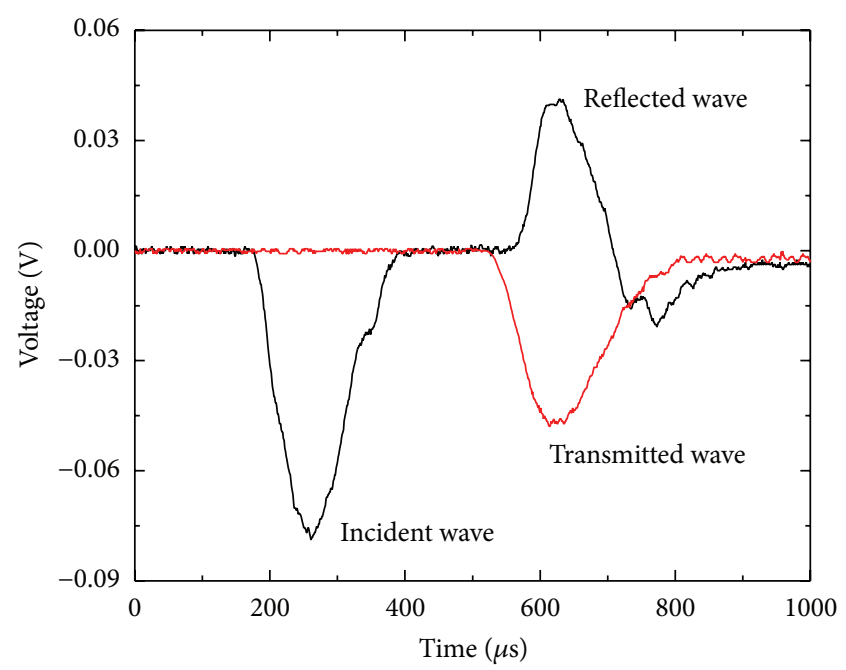

FIGURE 4: Electrical signals captured from strain gauges on the SHPB bars under impact load. 


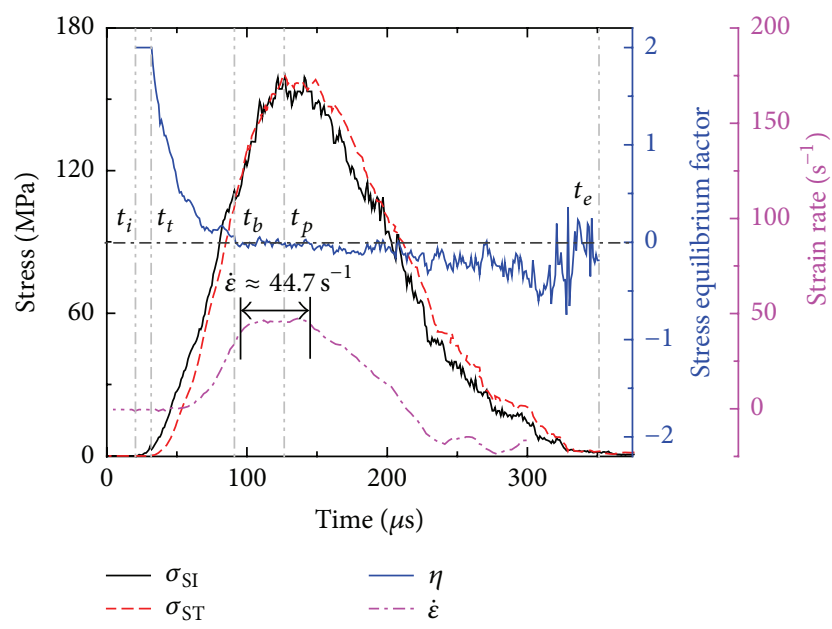

FIgURE 5: Stress equilibrium at the two ends of prismatic specimen under impact load.

Meanwhile, it shows that the stress equilibrium factor experiences several different stages during the loading process in Figure 5. With reference to the start to stop moments of each stage, the evolution of the stress state in the specimen can be specifically divided into the following four stages: (i) Stage $t_{i}$ to $t_{t}$ : The incident wave reaches the incident bar-specimen interface at time $t_{i}$, part of it reflected, and the remainder passes through the specimen and reaches the transmitted specimen-bar interface at time $t_{t}$. Since the stress at the transmitted end of the specimen is zero before $t_{t}$, the stress equilibrium factor remains at 2 . This phase lasted about 13 microseconds. (ii) Stage $t_{t}$ to $t_{b}$ : When the stress wave reaches the transmitted end of the specimen at time $t_{t}$, it moves back and forth in the specimen based on the reflected-transmitted law. Under about three internal reflections (approximately 66 microseconds) of a stress wave in the specimen, the value of $\eta$ decreases steadily from 2 to zero, which means that the stress equilibrium is achieved to some extent at time $t_{b}$. (iii) Stage $t_{b}$ to $t_{p}$ : From time $t_{b}$ to time $t_{p}$, the value of $\eta$ fluctuates slightly around zero, which indicates that the stress equilibrium is well maintained until the stress at the specimen's ends reaches the peak value. (iv) Stage $t_{p}$ to $t_{e}$ : After the time $t_{p}$, the stress equilibrium factor still remains near zero for several microseconds, and subsequently it fluctuates increasingly dramatically until the final time $t_{e}$. It represents that although the stress in the specimen reaches peak value, in a certain subsequent stage, the integrity of the specimen can still be well maintained; then, as microcracks in the specimen initiate, the reflectiontransmission coefficient is severely affected; in this case, the stress wave cannot freely propagate back and forth in the specimen. Additionally, noteworthy is the fact that although the value of $\eta$ fluctuates dramatically, it still remains around zero, which means that the specimen can still bear the load as an entirety and the stress equilibrium in the specimen can still be roughly sustained.

The analysis of the stress state evolution in the specimen reveals that the stress equilibrium can be achieved after approximately three internal reflections of a stress wave in the specimen and well maintained before the peak stress achieving. This result thus unveils the axial stress uniformity throughout the specimen during the dynamic loading process.

3.1.2. Strain Uniformity. In order to investigate the transverse strain uniformity in the specimen during loading process, strain outputs captured by the resistance strain gauges mounted on the specimen at different locations (see Figure 1) were compared. Strain results from gauges 2 and 4 were used to analyze the uniformity between the plate faces, and strain results from gauges 1,2 , and 3 were used to inspect the uniformity across the plate face. Figure 6 shows the strain data in the specimen under impact load with an average strain rate of about $45 \mathrm{~s}^{-1}$, where $t_{\mathrm{A}}$ corresponds to the arrival time of the incident compressive wave on the central cross section of the specimen, $t_{\mathrm{B}}$ corresponds to the moment of the peak stress of the loading compression wave reaching the central cross section of the specimen, and $t_{\mathrm{C}}$ corresponds to the terminated recording time of the oscilloscope (the total recording time of the oscilloscope is 1000 microseconds; the sampling frequency of the oscilloscope is once per microsecond); the period from $t_{\mathrm{A}}$ to $t_{\mathrm{B}}$ is the loading time of the specimen and the duration time from $t_{\mathrm{B}}$ to $t_{\mathrm{C}}$ corresponds to the unloading period.

Quantifying how well the correlation between strain channels is could be very objective if it is just by visible observation. The Russell error factor [27] is an impartial error measure method to eliminate any bias from the comparison. Russell error factor evaluates differences in phase and magnitude between two transient data sets to form a single comprehensive error factor $R_{C}$. The Russell correlation and error factor are calculated by the following equations:

$$
\begin{aligned}
\psi_{\mathrm{AA}} & =\sum_{i=1}^{N} f_{1}(i)^{2}, \\
\psi_{\mathrm{BB}} & =\sum_{i=1}^{N} f_{2}(i)^{2}, \\
\psi_{\mathrm{AB}} & =\sum_{i=1}^{N} f_{1}(i) f_{2}(i), \\
m & =\frac{\psi_{\mathrm{AA}}-\psi_{\mathrm{BB}}}{\sqrt{\psi_{\mathrm{AA}} \cdot \psi_{\mathrm{BB}}}}, \\
R_{M} & =\operatorname{sign}(m) \log _{10}(1+|m|), \\
R_{P} & =\frac{1}{\pi} \cdot \cos ^{-1}\left(\frac{\psi_{\mathrm{AB}}}{\sqrt{\psi_{\mathrm{AA}} \cdot \psi_{\mathrm{BB}}}}\right), \\
R_{C} & =\sqrt{\frac{\pi}{4}\left(R_{M}^{2}+R_{P}^{2}\right)},
\end{aligned}
$$

where $f_{1}$ and $f_{2}$ are the two vectors of transient data being considered and $f_{1}(i)$ and $f_{2}(i)$ refer to the values of the two vectors for each data point. $R_{M}, R_{P}$, and $R_{C}$ are the 
TABLE 2: Acceptance criteria for the Russell comprehensive error factor.

\begin{tabular}{lc}
\hline$R_{C}$ value & Assessment \\
\hline$R_{C} \leq 0.15$ & Excellent \\
$0.15<R_{C} \leq 0.28$ & Acceptable \\
$R_{C}>0.28$ & Poor \\
\hline
\end{tabular}

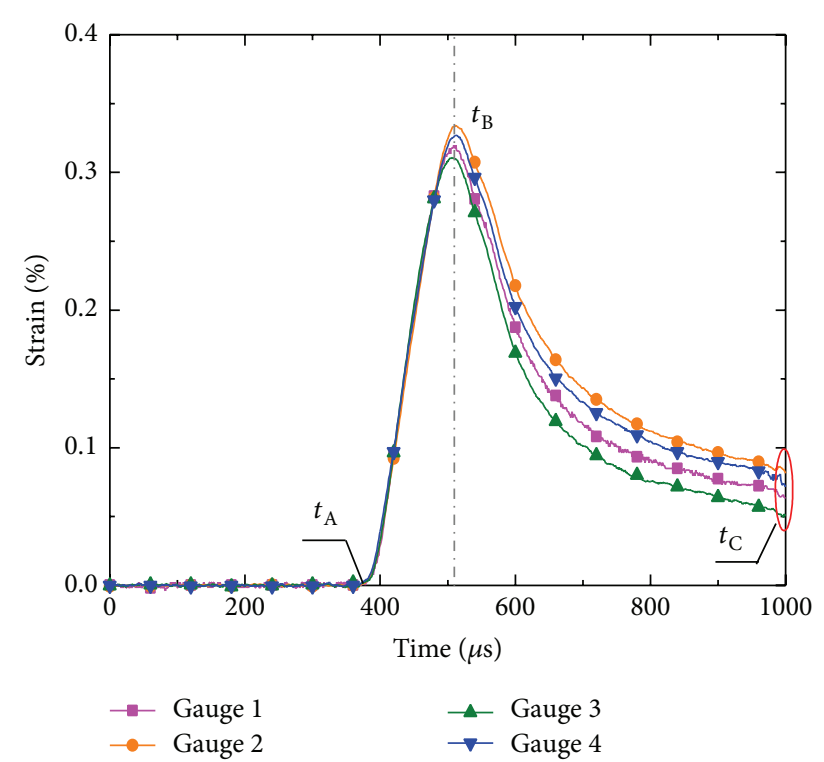

FIGURE 6: Strain signals captured by strain gauges on the specimen under impact load.

Russell magnitude, phase, and comprehensive error factor, respectively.

Though there is no definitive number that characterizes a "satisfactory" correlation between the data sets in all cases, the values listed in Table 2 have been agreed upon as a general guide and used to evaluate the correlation between the transient data sets [28]. These criteria are used in all comparisons that are made in support of this investigation.

With regard to the strain distribution in the specimen, the correlation between the strain profiles of gauges 2 and 4 from $t_{\mathrm{A}}$ to $t_{\mathrm{B}}$ in Figure 6 gives $R_{\mathrm{C}}$ value of 0.076 , which is classified as excellent. In terms of the comparison of strain profiles across the width of the specimen surface shown in Figure 6 between $t_{\mathrm{A}}$ and $t_{\mathrm{B}}$, the $R_{\mathrm{C}}$ values of gauges 1 and 2, gauges 1 and 3 , and gauges 2 and 3 are equal to $0.142,0.056$, and 0.164 , respectively, which are considered as excellent, excellent, and acceptable, respectively. Therefore, the statistics analysis reveals that the specimen was being loaded evenly and the principle of deformation uniformity in the specimen can be well guaranteed during the whole loading process.

3.1.3. Radial Inertial Effect Analysis. In SHPB experiments, the specimen is initially at rest and is expected to deform at a desired rate. Acceleration and thus inertia in both axial and radial directions accompany the strain rate change from zero to the desired level. The axial acceleration is accompanied by the inertia (or acceleration) in the radial direction due to
Poisson's effect [29]. Radial inertia will produce extra axial stress in specimen which should be significantly minimized.

Based on a first-order approximation for stress variation in the specimen, Davies and Hunter [30] derived the following relation, incorporating the correction for the radial inertia:

$$
\sigma(t)=\sigma_{\mathrm{ST}}+\rho_{s} \beta^{2}\left(\frac{1}{6} L_{s}^{2}-\frac{1}{2} v_{s}^{2} a^{2}\right) \ddot{\varepsilon}(t),
$$

where $\rho_{s}, v_{s}$, and $a$ are the density, Poisson's ratio, and the diameter of the specimen, respectively, $\beta(\approx 1)$ is a dimensionless parameter, and $\ddot{\varepsilon}(t)$ is the strain acceleration.

The second term on the right-hand side of (8) is inertia item, which can be eliminated or minimized from two aspects: (i) selecting a reasonable slenderness ratio and (ii) letting the strain acceleration vanish or be close to zero, namely, achieving constant strain rate loading.

In the present study, according to ISRM's recommendations [17], a slenderness ratio of 1.0 and a cone-shaped striker are adopted. The cone-shaped striker can generate wellrepeatable incident waves with slow rising that minimizes wave dispersion and facilitates stress equilibrium and constant strain rate deformation in specimen. The experimental result shows that dynamic stress equilibrium can be well guaranteed and relative constant strain rate loading has been achieved (see Figure 5). Moreover, the strain analysis in Section 3.1.2 has demonstrated that the specimen deformed uniformly over the transverse direction during the dynamic loading process. In light of these results, it can be concluded that the radial inertial effect has been minimized to a very low level.

3.2. Numerical Results. The numerical results of the dynamic stress-time curves of some selected elements in the cylindrical and prismatic specimens are shown in Figure 7. Table 3 also shows the maximum stress values of the corresponding elements in the specimens as shown in Figure 7. The axial stress was extracted at the centroid of each specified element.

In terms of the cylindrical specimen, it can be seen from Figure 7(a) and Table 3 that the stresses in the center of the cylindrical specimen $(\mathrm{C} 1, \mathrm{C} 2$, and $\mathrm{C} 3)$ show relatively higher values compared with those of the round elements (C4, C5, and C6), which may be caused by the radial inertial effect of the cylindrical specimen. However, this effect is limited (within 10 percent). The remainder of the cylindrical specimen is in a uniform stress state corresponding to the value in the center. Analysis of the data shows that there is a small coefficient of variance $(\mathrm{CV})$ in stress, which is less than $5 \%$ within the specimen. Even though there is spatial distribution of axial stress within the specimen, it is small and the entire specimen remains in a stress equilibrium state.

With regard to the prismatic specimen, both the contact interfaces, particularly at the corners (R7 and R9), show higher stress than those of the center element of the specimen (R1 to R6, see Figure 7(b) and Table 3). However, the stress difference in the specimen is also limited (within 10\%), which may be generated by end effect and 3-dimensional (3D) effect of the prismatic specimen. The stress in the center part of the specimen is uniform which is similar to that of the 


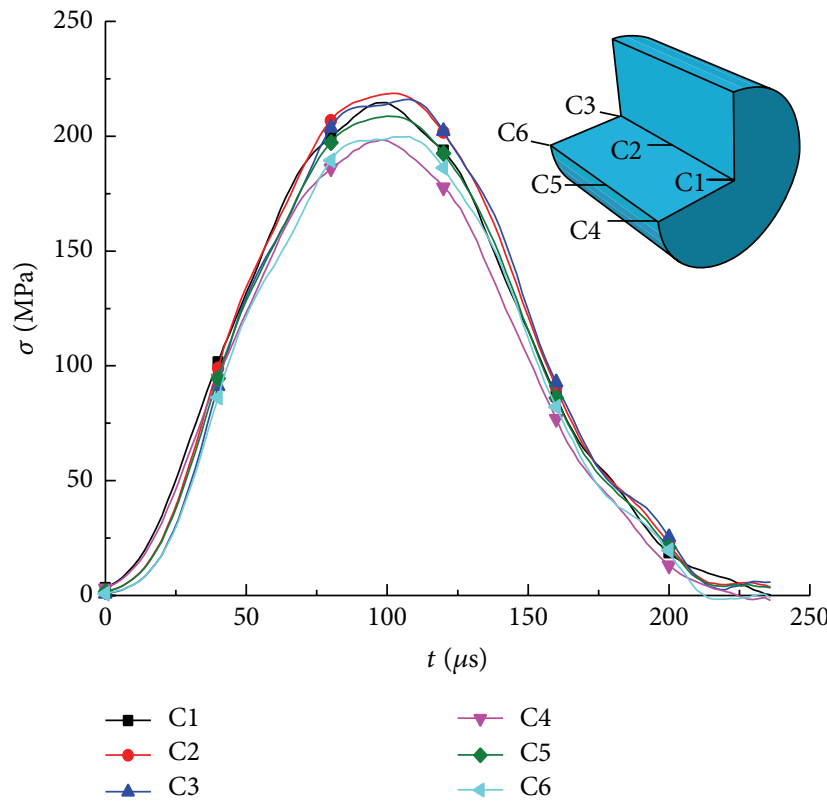

(a)

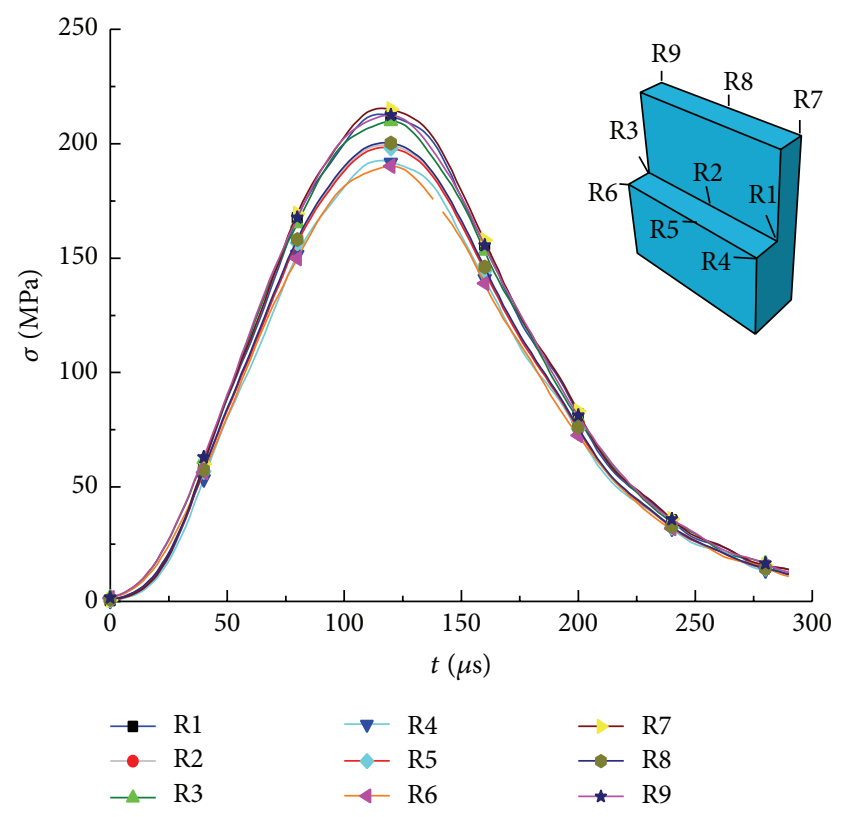

(b)

FIGURE 7: Numerical results of selected elements' stress-time curves in specimens under dynamic load: (a) cylindrical specimen and (b) prismatic specimen.

TABLE 3: Analysis of the peak stress of the selected elements in the cylindrical and prismatic specimens by numerical results.

\begin{tabular}{lcc}
\hline & Point & Stress (MPa) \\
\hline Cylindrical specimen & C1 & \\
Center & C2 & 214.6 \\
& C3 & 218.6 \\
& C4 & 216.1 \\
Round edge & C5 & 198.4 \\
& C6 & 208.7 \\
\hline Average & & 199.9 \\
Std. Dev. & & 209.4 \\
CV & & 8.58 \\
\hline Prismatic specimen & & $4.10 \%$ \\
Center & R1 & \\
& R2 & 212.9 \\
\hline \multirow{2}{*}{ Side center } & R3 & 199.4 \\
& R4 & 209.8 \\
\hline & R5 & 192.6 \\
Edge & R6 & 198.6 \\
& R7 & 190.2 \\
Average & R8 & 215.5 \\
CV & R9 & 200.4 \\
\hline
\end{tabular}

cylindrical specimen. Analogously, the analysis of stress in prismatic specimen in Table 3 also shows a small coefficient of variance (4.67\%); it indicates that the stress equilibrium can be achieved in the prismatic specimen despite the existence of local stress concentration in the corner of the prismatic edges. The result is consistent with the discussion on the stress equilibrium from the experiment in Section 3.1.

\section{Discussion and Verification}

In terms of the former stress and strain uniformity in specimen under dynamic loading, the specimens were not severely damaged in both the experimental and numerical studies, which indicate that the specimens are assumed to be in linear elastic state. However, in SHPB tests, rock specimens are always crushed. Therefore, in this section, both prismatic and cylindrical marble specimens are tested to compare the dynamic responses under different strain rates by SHPB. All the specimens are prepared from the same marble block. The dimensions of the tested specimens are provided in Table 4.

Figure 8 illustrates the comparison of experimental dynamic stress-strain curves of specimens with rectangular cross sections to those with circular cross sections. It can be seen that there is only slight difference between the experimental results. The three sets of specimens produce almost identical dynamic stress-strain curve shapes. Specifically, the deviation of the peak stress and the corresponding dynamic strain of rectangular specimens from cylindrical ones remains within $5 \%$ and $10 \%$ (Table 5), respectively. It shows that the specimen geometry will not affect the dynamic stress-strain curves significantly, provided that the specimen slenderness ratio is guided by ISRM's recommendation [17], and the interface between the bars and specimen is fully lubricated. This conclusion is consistent with the results by 
TABLE 4: The dimensions of marble specimens with different crosssectional shapes.

\begin{tabular}{rccccc}
\hline \multicolumn{2}{c}{ Specimen numbers } & $D^{*}(\mathrm{~mm})$ & $L(\mathrm{~mm})$ & $W(\mathrm{~mm})$ & $T(\mathrm{~mm})$ \\
\hline \multirow{4}{*}{ Cylindrical specimen } & C2 & 49.50 & 50.19 & & \\
& C3 & 49.50 & 50.02 & & \\
\hline \multirow{5}{*}{ Prismatic specimen } & R1 & & 50.20 & & \\
& R2 & & 45.33 & 45.74 & 15.23 \\
& R3 & & 45.97 & 45.88 & 15.20 \\
\end{tabular}

${ }^{*}$ Note: $D$, diameter.

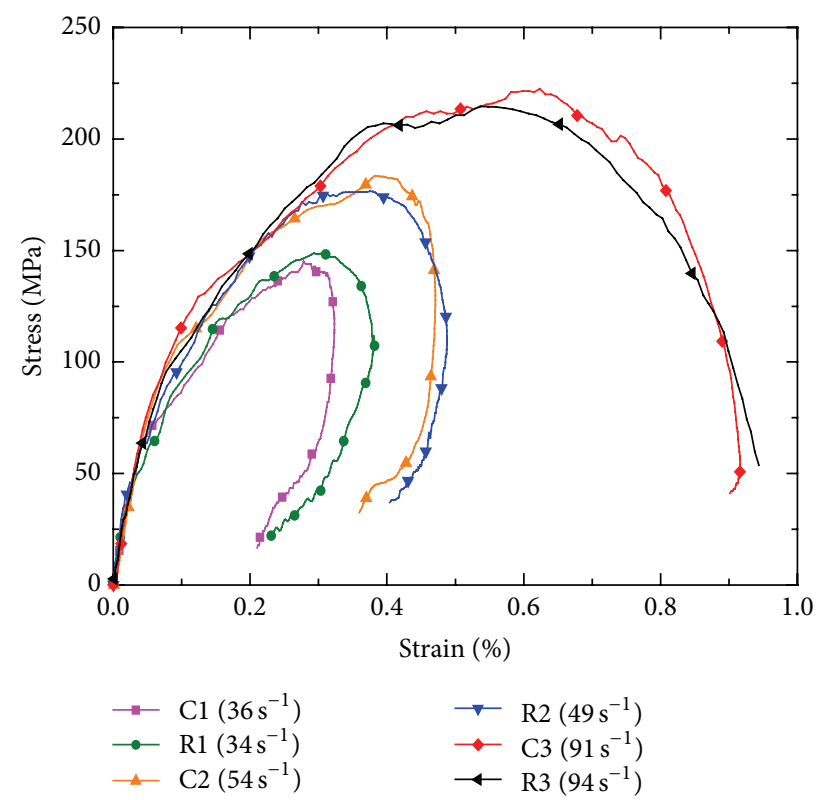

FIGURE 8: Comparison of the dynamic stress-strain curves of cylindrical and prismatic specimens under different strain rates $(\mathrm{C}$ represents circular cross-section; $\mathrm{R}$ represents rectangular crosssection).

Sen et al. [20], Woldesenbet and Vinson [21], and Pankow et al. [22], although the mechanical properties of the tested materials are different.

In order to investigate the effect of specimen shape on the failure mode under dynamic loading, high-speed photography technique and nuclear magnetic resonance imaging (NMRI) technology are adopted during and after the impact tests. A high-speed camera (Photron SA1.1) is used to capture the surface failure process with a setting speed of 50,000 frames per second (resolution: $320 \times 288$ ). A MiniMR-60 nuclear magnetic resonance instrument with a resolution of $100 \mu \mathrm{m}$ is utilized to scan and extract internal distribution of cracks generated by the dynamic loading within the recovered damaged specimen.

The typical surface failure modes of cylindrical and prismatic specimens in SHPB tests are shown in Figure 9. It can be seen that the failure mode of prismatic specimen is almost the same as that of the cylindrical one. Surface axial splitting fractures are the main failure mode of the marble specimen under uniaxial impact compression. However, Paliwal et al.
[31] have done Kolsky bar experiments on prismatic specimens of AlON, which is a transparent brittle polycrystalline ceramic material. Because of the transparency, they found that the dynamic failure of this material was not through axial splitting, even though it would seem so when the material was covered with an opaque layer of chromium. Huang et al. [32] reported using X-ray computed tomography (CT) scanning technology to examine the microscopic damage in rock specimen subjected to dynamic compressive loading. In this paper, a NMRI technology is used to examine the internal failure of the rock specimen after impact tests.

Both cylindrical and prismatic specimens prepared from the same marble block are tested by SHPB to avoid the crush of the marble specimen. The incident wave is controlled to a certain value, which can just generate visible cracks in the specimen. After tests, the specimen surface visible cracks are carefully recorded by photography. Figures 10 and 11 show the visible surface cracks of prismatic and cylindrical specimens. It can be clearly seen that the loading direction parallel to surface cracks occurs in the prismatic marble specimen in Figure 10. By the surface cracks trajectory, it can be inferred that the dominant failure mode of the rock will be axial splitting fractures if the specimen is totally crushed. For the cylindrical marble specimen, as shown in Figure 11, some visible surface cracks can be observed in the impact loading contact surface. Meanwhile, a visible axial splitting crack also occurred along the impact loading direction.

Even though the axial splitting cracks are easy to observe in the surface of the rock specimen, the internal damage or failure of the rock is difficult to identify. Therefore, both the damaged cylindrical and prismatic marble specimens (water saturated after SHPB test) are detected by NMRI to detect the internal failure of the marble specimen. The NMRI equipment is shown in Figure 12.

Figure 13 shows typical NMRI photos of cylindrical and prismatic marble specimen in three loading direction parallel sections. The white part of the photo means that water is detected by NMRI and this region represents damage or failure that occurs inside of the specimen. Due to the low porosity $(0.24 \%-0.57 \%)$ of the marble specimen, it is quite difficult to obtain good internal damage information of the marble by the NMRI detecting method. However, it can be found that some loading directions parallel cracks or fissures have been detected in the internal part of the specimen, particularly the prismatic specimen. By studying the failure modes of the prismatic and cylindrical specimens under impact loading, it shows that the change of the specimen shape from cylindrical to prismatic type will not significantly affect the failure mode of the intact marble specimen with the same $L / D$ or $L / W$ ratio of 1.0 .

\section{Application of Prismatic Rock Specimen in Dynamic Crack Propagation}

Since dynamic loads (e.g., drilling, blasting, earthquakes, and rock burst) widely existed in mining and geotechnical engineering practice, it is of great significance to study the characteristics and mechanism of cracking process within 


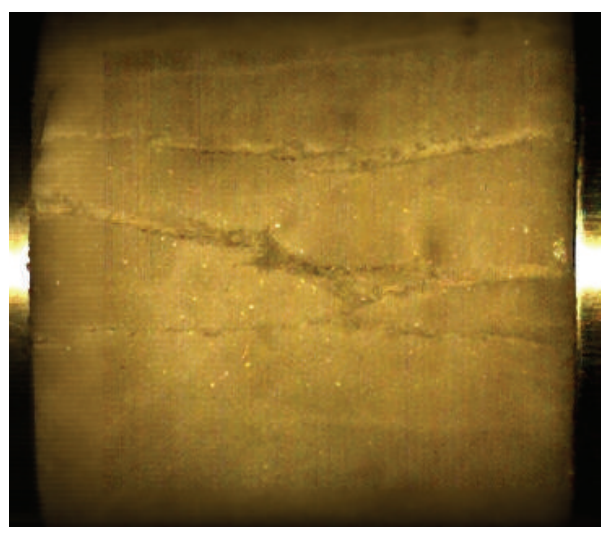

(a)

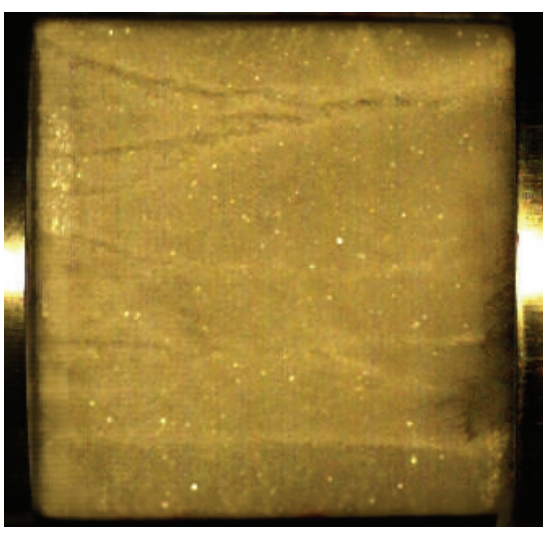

(b)

FIGURE 9: Typical failure mode of cylindrical and prismatic specimens in SHPB test: (a) cylindrical specimen C3 and (b) prismatic specimen R3 (impact loading direction: from right to left).



Observing side surface

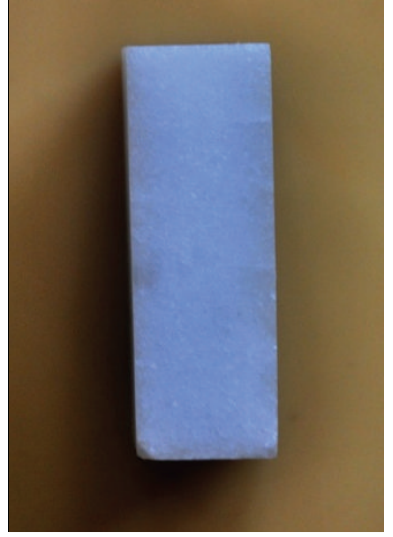

Loading contact surface

FIGURE 10: Visible surface cracks of prismatic marble specimen under certain impact load by SHPB.

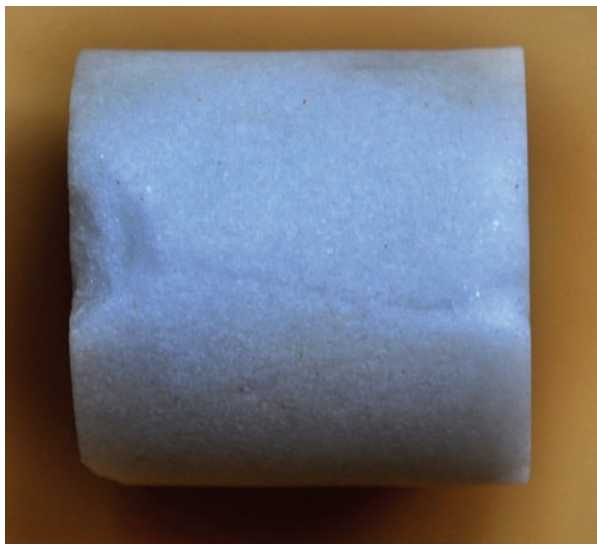

Observing side surface

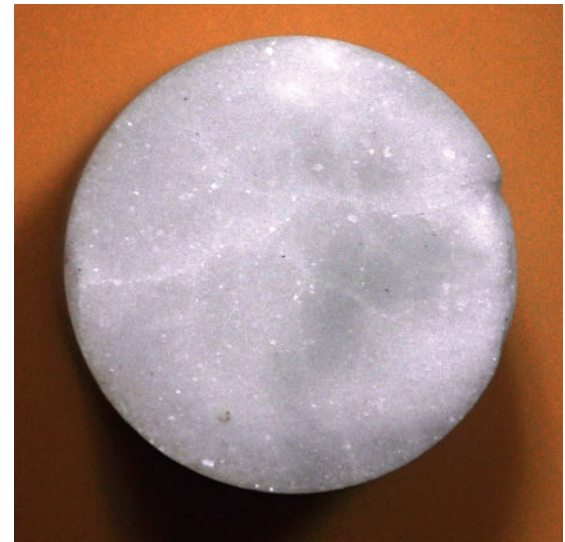

Loading contact surface

FIGURE 11: Visible surface cracks of cylindrical marble specimen under certain impact load by SHPB. 
TABLE 5: Comparison of the peak stress and the corresponding dynamic strain values between prismatic and cylindrical specimens under approximately equal strain rates.

\begin{tabular}{lccccc}
\hline Specimen & $\dot{\varepsilon} / \mathrm{s}^{-1}$ & Stress/MPa & Stress deviation & Strain (\%) & Strain deviation \\
\hline C1 & 36 & 145.16 & $2.45 \%$ & $0.29 \%$ & $0.30 \%$ \\
R1 & 34 & 148.72 & $3.76 \%$ & $0.39 \%$ & $6.29 \%$ \\
\hline C2 & 54 & 183.40 & & $0.38 \%$ & $2.85 \%$ \\
R2 & 49 & 176.50 & $3.57 \%$ & $0.60 \%$ & $8.82 \%$ \\
\hline C3 & 91 & 222.47 & & $0.55 \%$ & \\
R3 & 94 & 214.53 & & & \\
\hline
\end{tabular}

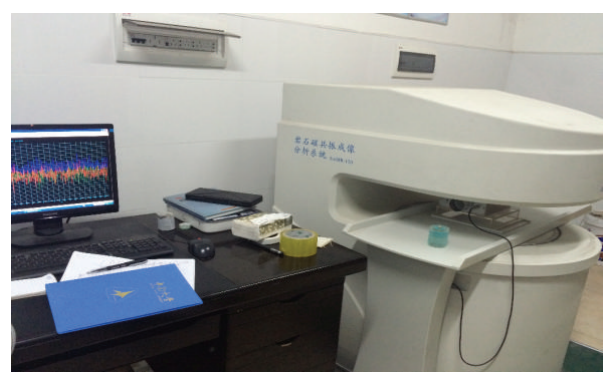

FiguRE 12: A MiniMR-60 nuclear magnetic resonance instrument (NMRI) for rocks.
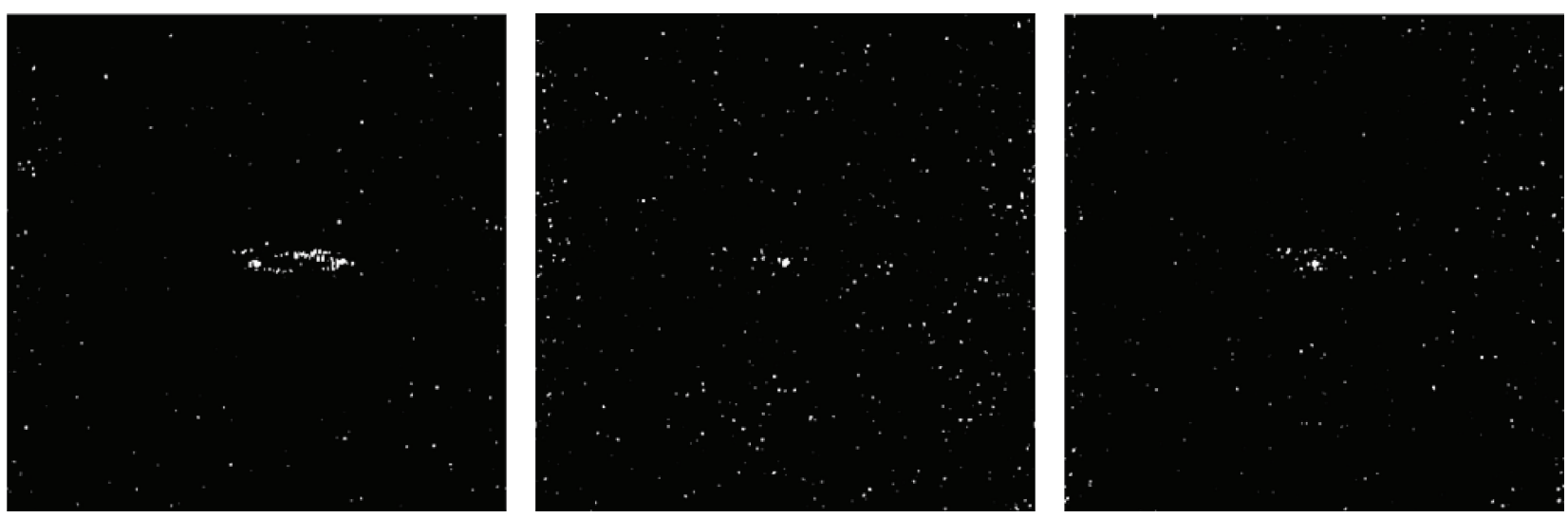

(a)
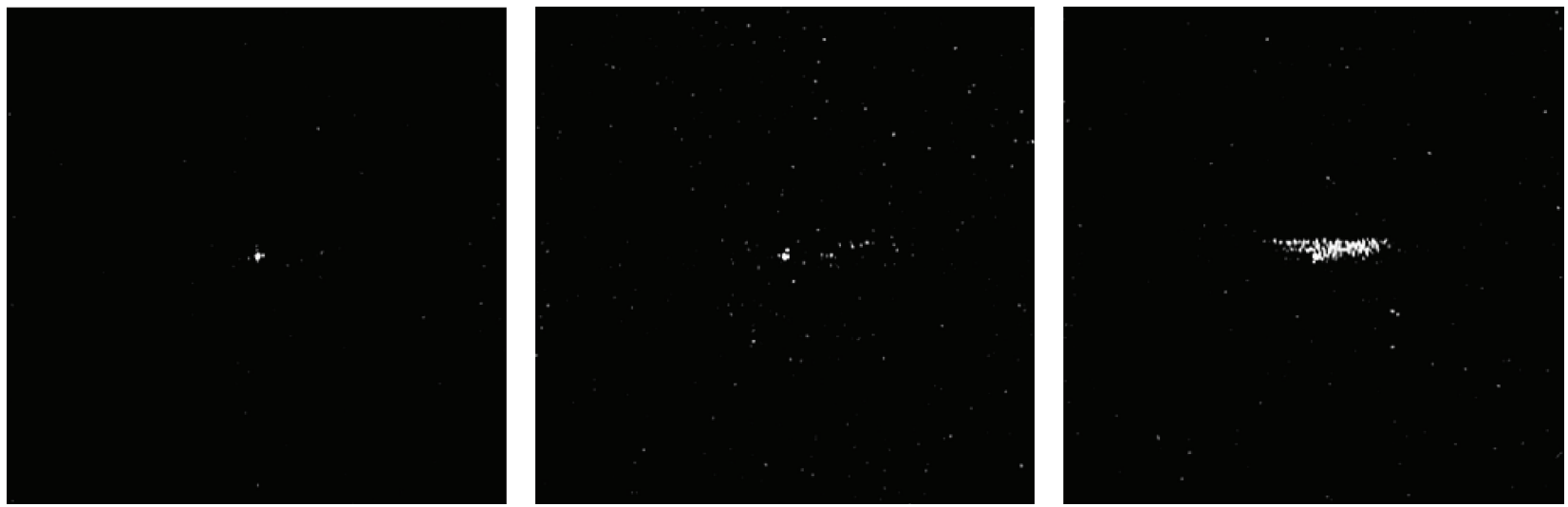

(b)

FIGURE 13: Typical NMRI photos of cylindrical and prismatic marble specimen in three loading direction parallel sections: (a) cylindrical specimen and (b) prismatic specimen (note: the white part of the photo means that water is detected by NMRI and this region represents damage or failure occurring inside of the specimen; impact loading direction of the specimen: from right to left). 

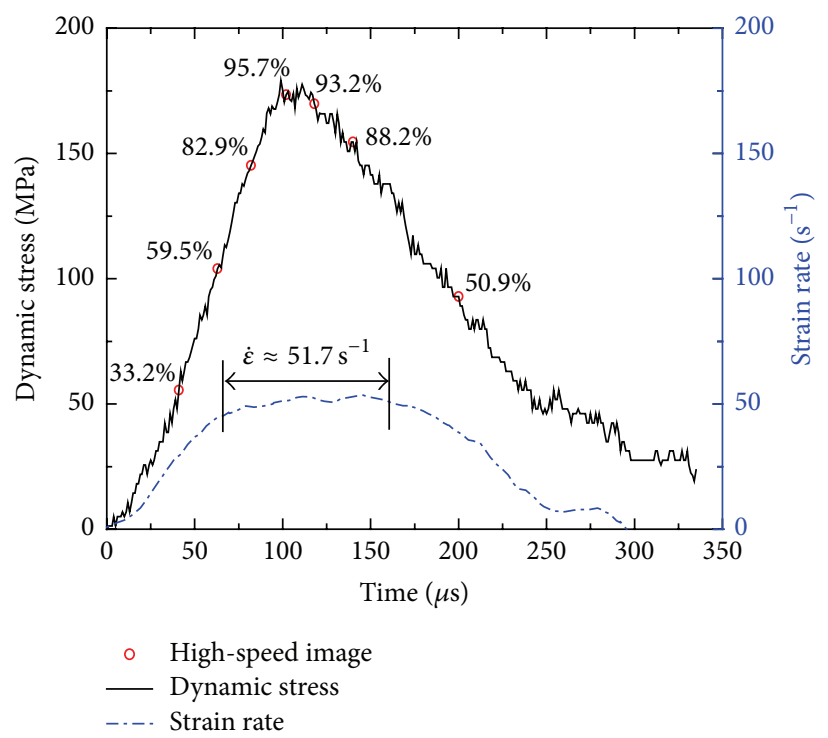

(a)
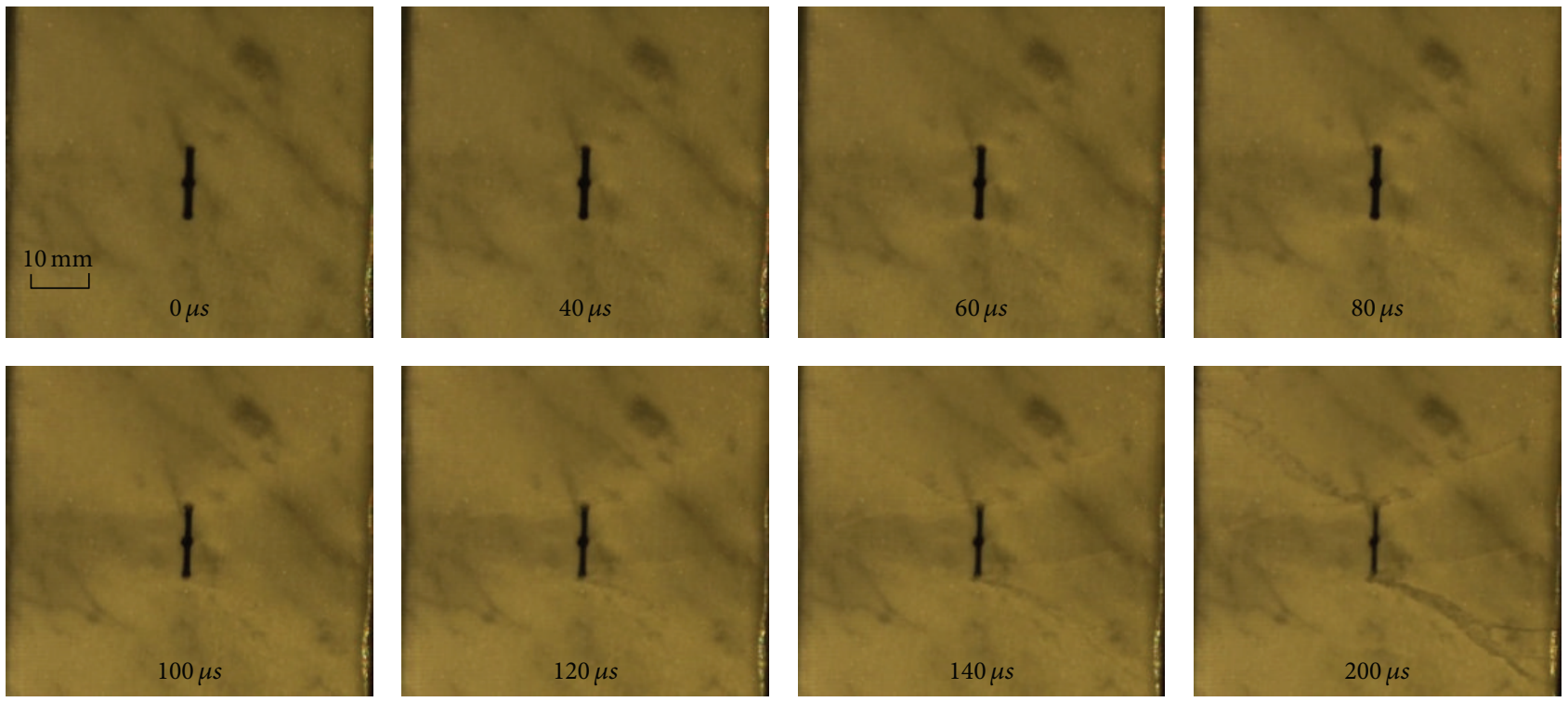

(b)

FIGURE 14: Typical real time of crack propagation in prismatic marble specimen with a vertical single preexisting flaw. (a) Complete stress-time and strain rate-time curves and (b) high-speed images at different stages (impact loading direction: from right to left).

flawed specimens with respect to guiding the drill and blast method of rock breaking, dynamic designing, and protecting of rock engineering. It will be helpful to study the dynamic rock fracturing process by using prismatic specimens by SHPB.

Based on the forgoing analysis, a series of dynamic impact experiments are performed with prismatic marble specimens containing a single penetrated flaw, aiming to preliminarily investigate the effects of the preexisting $2 \mathrm{D}$ flaw on the dynamic cracking process and failure modes with the aid of high-speed photography technique under impact loads.

Figure 14 shows a typical fracturing process under an average strain rate of $51.7 \mathrm{~s}^{-1}$. It can be seen from Figure 14 that white patches begin to develop at the tips of the fissure as dynamic stress loaded to $33.2 \%$ of peak stress at the time of 40 microseconds; then, as the load continuously increases, the white patches are widened, intensified in color, and lengthened to form an " $\mathrm{X}$ " shaped white belt, extending from the flaw tips to the boundary of specimen. When the specimen is loaded to $167.8 \mathrm{MPa}$ ( $95.7 \%$ of peak stress) at the time of 100 microseconds, shear cracks, characterized by rough texture and pulverized rock powder, initiated at the down tip of the flaw. Subsequently, as the dynamic stress is unloaded during the postpeak period, shear cracks are lengthened and widened approximately along the diagonal direction. Meanwhile, secondary cracks, tensile wing cracks, are characterized by smoothly plumose texture, emanating from the upper and down tips of the flaw and propagating 
approximately along the axial direction. After that, shear cracks continue to rapidly propagate and develop and lead to the final failure of the specimen.

In general, the whole cracking process of the perpendicular single-flawed specimens to the loading direction can be classified into four main stages. Firstly, white patches initiate and propagate during linear elastic stage; then, shear cracks as the first cracks emanate at or near the tips of the flaw in the trajectories of the white patches marginally prior to or later than the peak stress; thirdly, secondary tensile and/or shear cracks initiate along with the propagation of the shear cracks; finally, the first and secondary cracks propagate and coalesce with each other which lead to the final failure of the specimen. It needs to be noted that shear cracks are the first cracks in flawed specimens under dynamic loading, which dominated in crack propagation process and usually developed into an "X" shaped shear belt in the flawed specimen. The failure process of single-flawed marble specimen is different from that of the intact marble specimen.

\section{Conclusions}

By checking the stress and strain evolutions in the prismatic rock specimen under impact load by round bars, the stress equilibrium reveals that the specimen deforms homogeneously. The comparative experiments by prismatic and cylindrical specimens under different strain rates indicate that the change of the specimen's shape from cylindrical to prismatic type only has slight effects on the dynamic responses of the tested specimens under impact load. In general, the experimental and numerical analyses prove that the prismatic rock specimens are feasible and valid to use in SHPB test. The present work reveals that it will be possible to investigate the crack propagation and failure mechanisms from the flat side surface of the prismatic specimens by highspeed imaging technique in SHPB tests. It is a benefit for rock mechanics to extend the researches on crack propagation from quasistatic status to dynamic status by using prismatic rock specimens with preexisting flaws.

\section{Competing Interests}

The authors declare that they have no competing interests.

\section{Acknowledgments}

The present research is financially supported by the National Natural Science Foundation of China (nos. 51404250, 11102239, and 11472311), the Program for New Century Excellent Talents in University (no. NCET-13-0588), and the Innovation Driven Plan in Central South University (no. 2015CXS016).

\section{References}

[1] M. Sagong and A. Bobet, "Coalescence of multiple flaws in a rock-model material in uniaxial compression," International Journal of Rock Mechanics and Mining Sciences, vol. 39, no. 2, pp. 229-241, 2002.
[2] H. Lee and S. Jeon, "An experimental and numerical study of fracture coalescence in pre-cracked specimens under uniaxial compression," International Journal of Solids and Structures, vol. 48, no. 6, pp. 979-999, 2011.

[3] J. Miller and H. Einstein, "Crack coalescence tests on granite," in Proceedings of the 42nd US Rock Mechanics Symposium (USRMS '08), American Rock Mechanics Association, 2008.

[4] J. Huang, G. Chen, Y. Zhao, and R. Wang, "An experimental study of the strain field development prior to failure of a marble plate under compression," Tectonophysics, vol. 175, no. 1-3, pp. 269-284, 1990.

[5] L. N. Y. Wong and H. H. Einstein, "Crack coalescence in molded gypsum and carrara marble: part 1. Macroscopic observations and interpretation," Rock Mechanics and Rock Engineering, vol. 42, no. 3, pp. 475-511, 2009.

[6] Y. Fujii and Y. Ishijima, "Consideration of fracture growth from an inclined slit and inclined initial fracture at the surface of rock and mortar in compression," International Journal of Rock Mechanics and Mining Sciences, vol. 41, no. 6, pp. 1035-1041, 2004.

[7] S.-Q. Yang and H.-W. Jing, "Strength failure and crack coalescence behavior of brittle sandstone samples containing a single fissure under uniaxial compression," International Journal of Fracture, vol. 168, no. 2, pp. 227-250, 2011.

[8] B. Shen, "The mechanism of fracture coalescence in compression-experimental study and numerical simulation," Engineering Fracture Mechanics, vol. 51, no. 1, pp. 73-85, 1995.

[9] A. Bobet and H. H. Einstein, "Fracture coalescence in rocktype materials under uniaxial and biaxial compression," International Journal of Rock Mechanics and Mining Sciences, vol. 35, no. 7, pp. 863-888, 1998.

[10] C. H. Park and A. Bobet, "Crack initiation, propagation and coalescence from frictional flaws in uniaxial compression," Engineering Fracture Mechanics, vol. 77, no. 14, pp. 2727-2748, 2010.

[11] R. H. C. Wong, K. T. Chau, C. A. Tang, and P. Lin, "Analysis of crack coalescence in rock-like materials containing three flaws-part I: experimental approach," International Journal of Rock Mechanics and Mining Sciences, vol. 38, no. 7, pp. 909-924, 2001.

[12] R. H. C. Wong and K. T. Chau, "Crack coalescence in a rock-like material containing two cracks," International Journal of Rock Mechanics and Mining Sciences, vol. 35, no. 2, pp. 147-164, 1998.

[13] G. Gao, S. Huang, K. Xia, and Z. Li, "Application of Digital Image Correlation (DIC) in Dynamic Notched Semi-Circular Bend (NSCB) tests," Experimental Mechanics, vol. 55, no. 1, pp. 95-104, 2015.

[14] C. Zou and L. N. Y. Wong, "Experimental studies on cracking processes and failure in marble under dynamic loading," Engineering Geology, vol. 173, pp. 19-31, 2014.

[15] D. Li, T. Cheng, T. Zhou, and X. Li, "Experimental study of the dynamic strength and fracturing characteristics of marble specimens with a single hole under impact loading," Yanshilixue Yu Gongcheng Xuebao/Chinese Journal of Rock Mechanics and Engineering, vol. 34, no. 2, pp. 249-260, 2015.

[16] H. Kolsky, "An investigation of the mechanical properties of materials at very high rates of loading," Proceedings of the Physical Society-Section B, vol. 62, no. 11, article 676, 1949.

[17] Y. X. Zhou, K. Xia, X. B. Li et al., "Suggested methods for determining the dynamic strength parameters and mode-I fracture toughness of rock materials," International Journal of Rock Mechanics and Mining Sciences, vol. 49, pp. 105-112, 2012. 
[18] B. Song, W. Chen, Y. Ge, and T. Weerasooriya, "Dynamic and quasi-static compressive response of porcine muscle," Journal of Biomechanics, vol. 40, no. 13, pp. 2999-3005, 2007.

[19] F. Ferreira, M. A. Vaz, and J. A. Simões, "Mechanical properties of bovine cortical bone at high strain rate," Materials Characterization, vol. 57, no. 2, pp. 71-79, 2006.

[20] O. Sen, S. A. Tekalur, and P. Maity, "On the use of noncylindrical specimens in a split-Hopkinson pressure bar," The Journal of Strain Analysis for Engineering Design, vol. 46, no. 8, pp. 866-878, 2011.

[21] E. Woldesenbet and J. R. Vinson, "Specimen geometry effects on high-strain-rate testing of graphite/epoxy composites," AIAA Journal, vol. 37, no. 9, pp. 1102-1106, 1999.

[22] M. Pankow, C. Attard, and A. M. Waas, "Specimen size and shape effect in split Hopkinson pressure bar testing," The Journal of Strain Analysis for Engineering Design, vol. 44, no. 8, pp. 689698, 2009.

[23] H. Kolsky, Stress Waves in Solids, Clarendon Press, Oxford, UK, 1953.

[24] Z. Zhou, X. Li, Z. Ye, and K. Liu, "Obtaining constitutive relationship for rate-dependent rock in SHPB tests," Rock Mechanics and Rock Engineering, vol. 43, no. 6, pp. 697-706, 2010.

[25] X. Li, Z. Zhou, T.-S. Lok, L. Hong, and T. Yin, "Innovative testing technique of rock subjected to coupled static and dynamic loads," International Journal of Rock Mechanics and Mining Sciences, vol. 45, no. 5, pp. 739-748, 2008.

[26] X. Li, Y. Zou, and Z. Zhou, "Numerical simulation of the rock SHPB test with a special shape striker based on the discrete element method," Rock Mechanics and Rock Engineering, vol. 47, no. 5, pp. 1693-1709, 2014.

[27] D. M. Russell, "Error measures for comparing transient data: part I: development of a comprehensive error measure," in Proceedings of the 68th Shock and Vibration Symposium, pp. 175184, Hunt Valley, Md, USA, 1997.

[28] D. Russell, "DDG53 shock trial simulation acceptance criteria," in Proceedings of the 69th Shock and Vibration Symposium, pp. 12-19, 1998.

[29] W. W. Chen and B. Song, Split Hopkinson (Kolsky) Bar: Design, Testing and Applications, Springer Science \& Business Media, Berlin, Germany, 2010.

[30] E. D. H. Davies and S. C. Hunter, "The dynamic compression testing of solids by the method of the split Hopkinson pressure bar," Journal of the Mechanics and Physics of Solids, vol. 11, no. 3, pp. 155-179, 1963.

[31] B. Paliwal, K. T. Ramesh, and J. W. McCauley, "Direct observation of the dynamic compressive failure of a transparent polycrystalline ceramic (AION)," Journal of the American Ceramic Society, vol. 89, no. 7, pp. 2128-2133, 2006.

[32] S. Huang, K. Xia, and H. Zheng, "Observation of microscopic damage accumulation in brittle solids subjected to dynamic compressive loading," Review of Scientific Instruments, vol. 84, no. 9, Article ID 093903, 2013. 


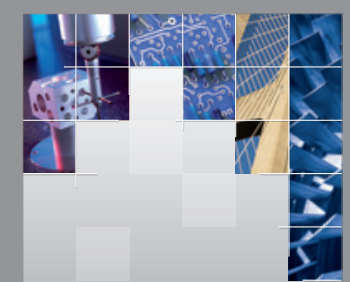

\section{Enfincering}
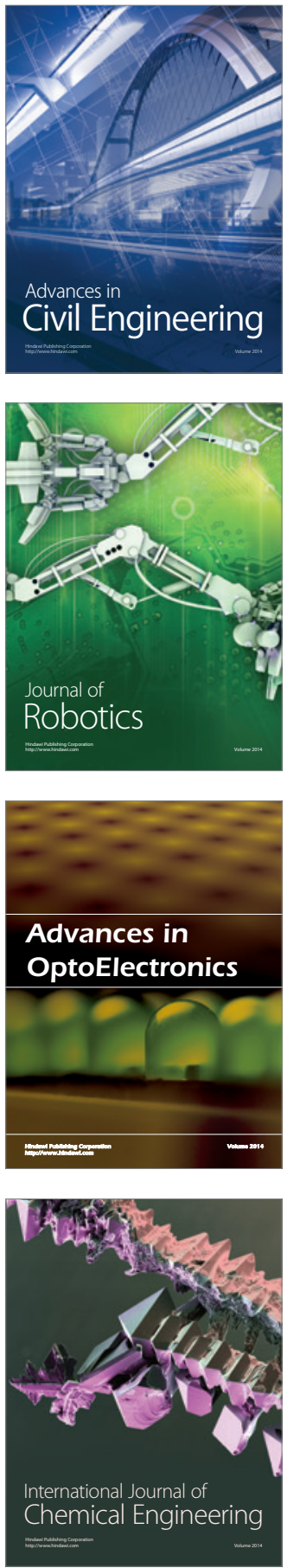

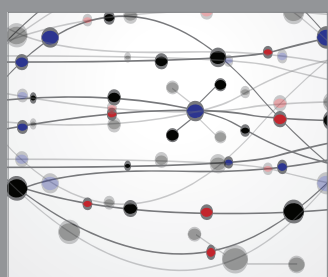

The Scientific World Journal

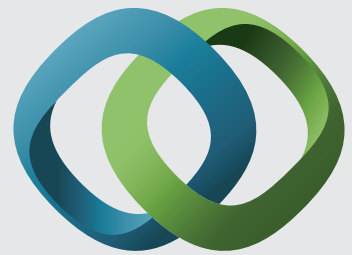

\section{Hindawi}

Submit your manuscripts at

http://www.hindawi.com
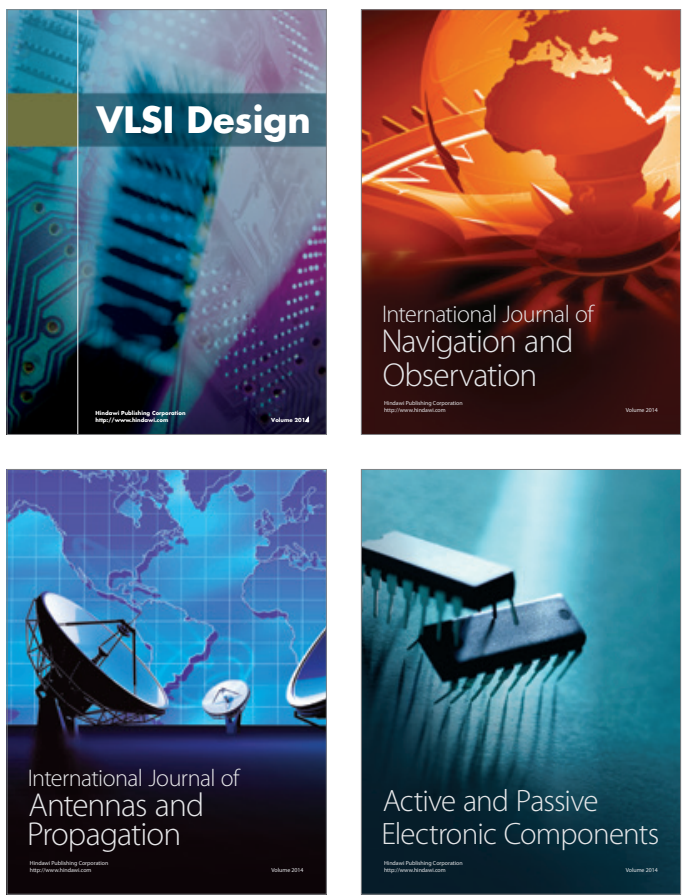
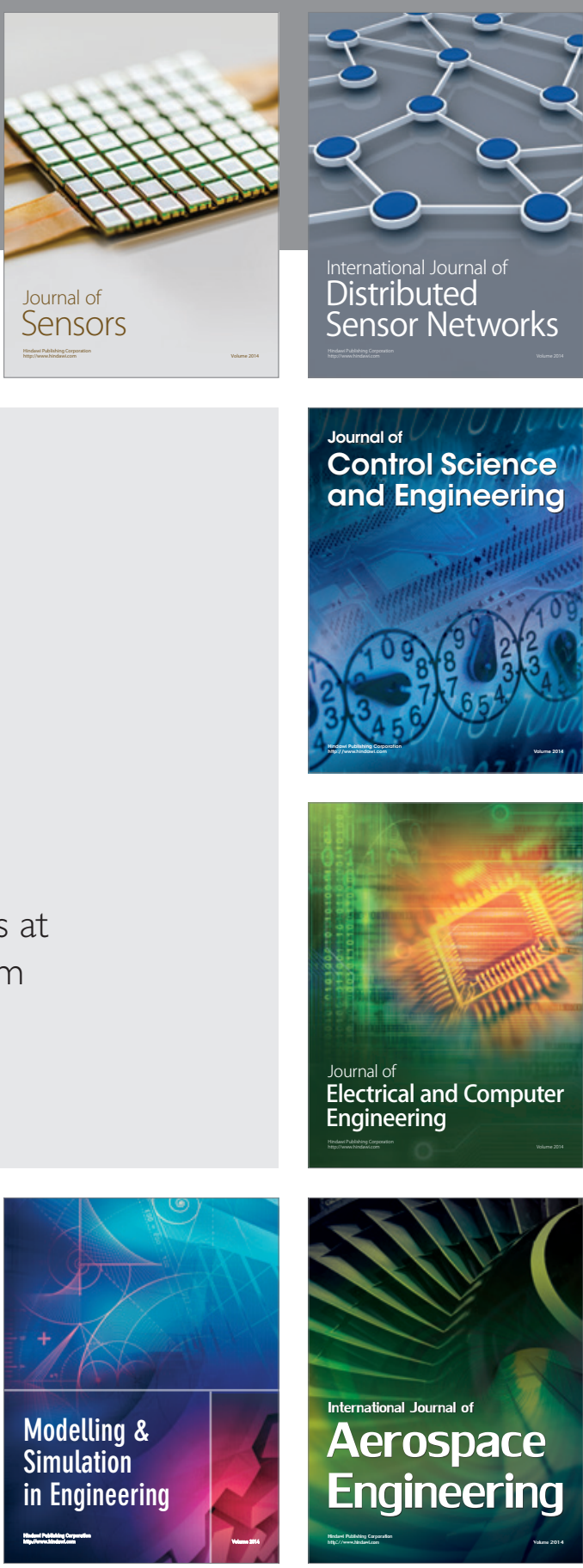

International Journal of

Distributed

Sensor Networks

Journal of

Control Science

and Engineering
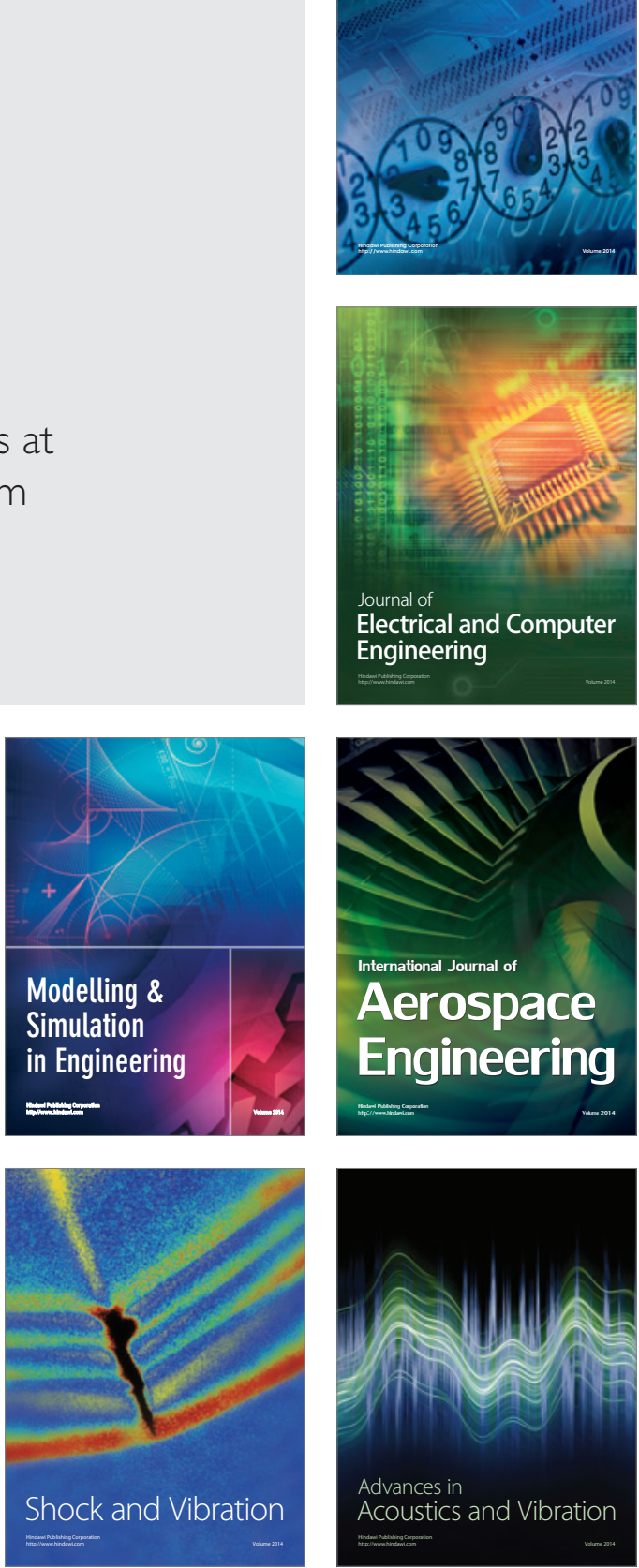